УДК 336.1

\title{
ПУТИ ПОВЫШЕНИЯ ЭФФЕКТИВНОСТИ \\ СИСТЕМЫ ФИНАНСОВОГО МОНИТОРИНГА: \\ СРАВНЕНИЕ РОССИЙСКОЙ И ЗАРУБЕЖНЫХ СИСТЕМ ПОД/ФТ
}

\section{Блинова Елена Дмитриевна Закирова Элина Рафиковна}

ФБОУ ВО «Уральский государственный экономический университет»

Аннотация: Статья посвящена вопросу эффективности применяемых мер по борьбе с отмыванием денег и финансированием терроризма (ОД/ФТ) в таких странах, как Россия, США, Норвегия, Великобритания, Китай, Кувейт и Япония. Актуальность исследования обусловлена тем, что Группой разработки финансовых мер борьбы с отмыванием денег (ФАТФ), которая устанавливает общепризнанные международные стандарты в сфере ПОД/ФТ, ежегодно проводится оценка эффективности национальных систем финансового мониторинга, по результатам которой исследуемая страна может быть поставлена на регулярный мониторинг с закреплением за этой страной обязанности устранить выявленные недочёты в течение определённого времени. Кроме того, проблема эффективного противодействия легализации преступных доходов исследуются учёными и действующими специалистами уже несколько десятилетий подряд. Среди наиболее значимых в этой области следует выделить научные работы: Аблаевой Т.Д., Бондарь А.П., Братко А.Г., Бурцева В.В., Глотова В.И., Кондратьевой Е.А., Овсянникова С.В., Прошунина М.М., Чиханчина Ю.А. и другие. Тем не менее, анализ работ указанных авторов [2-16], а также международных и национальных правовых актов [1, 17-22] выявил ряд нерешённых проблем в содержании системы финансового мониторинга, а также противоречивость в определении её эффективности.

В рамках исследования применены общенаучные методы исследования (анализ, синтез, обобщение, индукция и дедукция, аналогия) и методы эмпирических исследований (использование статистики). В частности, проведён сравнительный анализ эффективности систем финансового мониторинга в заявленных странах по показателю чистого притока (оттока) капитала в процентном отношении к ВВП и по оценкам, которые были 
получены от экспертов ФАТФ. По итогам проведённого исследования выявлены преимущества и недостатки каждой из рассмотренных систем, а также предложены мероприятия по повышению эффективности российской системы финансового мониторинга. Полученные выводы могут быть использованы как специалистам в сфере финансового мониторинга с целью пересмотра применяемых мер в рамках ПОД/ФТ, так и исследователями при написании научных работ.

Ключевые слова: финансовый мониторинг; противодействие отмыванию денег и финансированию терроризма; ПОД/ФТ; эффективность системы финансового мониторинга; ФАТФ.

\section{WAYS TO IMPROVE THE EFFECTIVENESS OF AML/CFT SYSTEMS: COMPARISON OF THE RUSSIAN AND FOREIGN METHODS}

\section{Blinova Elena Dmitrievna Zakirova Elina Rafikovna}

Abstract: This paper is devoted to the effectiveness of anti-money laundering and counter-terrorist financing (AML/CFT) systems in countries such as Russia, the USA, Norway, Britain, China, Kuwait, and Japan. Annually the Financial Action Task Force (FATF), which establishes generally recognized international standards in AML/CFT, assesses the effectiveness of national AML/CFT systems. Based on the assessment results, the FATF can put the country understudy on regular monitoring with an obligation to eliminate the identified deficiencies within a particular time. Scientists and specialists have also studied the problem of effective counteraction to money laundering for several decades in a row. Among the most significant in this area are the scientific works of Ablaeva T.D., Bondar A.P., Bratko A.G., Burtsev V.V., Glotov V.I., Kondratyeva E.A., Ovsyannikov S.V., Proshunin M.M., Chikhanchina Yu. A., and others. Nevertheless, an analysis of these works [2-16] and international and national legal acts [1, 17-22] revealed several unsolved problems in the context of the AML/CFT system and inconsistency in determining its effectiveness.

In the study framework, general scientific research methods (analysis, synthesis, generalization, induction and deduction, analogy) and methods of empirical research (use of statistics) were used. The comparative analysis of the AML/CFT systems' effectiveness in countries declared by net inflow (outflow) of 
capital as a percentage of GDP and results that the FATF experts received. As a result, each of the considered systems' advantages and disadvantages was revealed, and measures to improve the Russian AML/CFT system's efficiency were proposed. The findings can be used by both specialists in financial monitoring to revise the applied AML/CFT measures and researchers to write scientific papers.

Key words: financial monitoring; anti-money laundering and combating the financing of terrorism; AML/CFT; the effectiveness of the AML/CFT system; FATF.

\section{Введение}

Как известно, легализация доходов, которые были получены в результате незаконной деятельности, является глобальной угрозой экономической, политической и социальной безопасности. Первыми с проблемой ОД столкнулись США и Куба, где в 1930-х годах в казино к легальной выручке подмешивались «грязные деньги».

Другой, не менее значимой проблемой является финансирование терроризма. Печальным примером необходимости постановки задачи противодействия ФТ являются события начала XXI века - террористические акты, крупнейшими из которых стали: 11 сентября 2001 года (башни-близнецы) в США; с 23 по 26 октября 2002 года («Норд-Ост») и с 1 по 3 сентября 2004 года (Беслан) в России.

Таким образом, ПОД/ФТ является одним из важнейших стратегических направлений обеспечения безопасности любого государства. А обострившиеся в 2000-х проблемы противодействия незаконным финансовым операциям и терроризму привели к становлению такой науки, как финансовый мониторинг.

Термин «мониторинг» переводится с английского как непрерывное наблюдение за каким-либо процессом с целью выявления его соответствия желаемому результату или первоначальным предположениям. Под «финансовым мониторингом» в первую очередь понимают систему процедур, основная цель которых заключается в оценке законности и правильности формирования и использования денежных доходов, накоплений и поступлений у субъектов хозяйствования, а главной задачей выступает противодействие проникновению в легальную экономику денежных средств, которые получены незаконным путём или направлены на финансирование терроризма [15]. Кроме того, «финансовый мониторинг» представляет собой сложную предметную область, которая включает в себя основы финансового, правового и административного регулирования, межведомственных и межгосударственных 
взаимоотношений. Следовательно, понятие «финансовый мониторинг» является также частью правоохранительной системы [4].

Как говорилось ранее, США самой первой столкнулась с угрозой легализации преступных доходов и постепенно начала формировать и развивать систему финансового мониторинга в стране. На сегодняшний день уже в большинстве стран мира разработаны и внедрены свои национальные системы. Кроме того, все эти страны принимают согласованные меры в рамках ПОД/ФТ не только на национальном, но и на международном уровне.

В 1989 году по решению стран «Большой семёрки» была создана межправительственная организация ФАТФ, которая стала основным международным институтом, целью создания которого является разработка и внедрение международных стандартов в сфере ПОД/ФТ, а также оценка соответствия национальных систем финансового мониторинга этим стандартам. Членами ФАТФ являются 34 страны и 2 международные организации, наблюдателями - 20 организаций и 2 страны, а число исследуемых национальных систем ПОД/ФТ уже составляет 228. Стоит отметить, что основным инструментом ФАТФ в реализации своего мандата являются 40 рекомендаций, которые представляют собой всеобъемлющий свод организационно-правовых мер по созданию в каждой стране эффективного режима ПОД/ФТ и подвергаются ревизии в среднем один раз в пять лет.

\section{Анализ эффективности российской и зарубежных систем ПОД/ФТ}

Согласно проводимым исследованиям $[9,11,17]$ одним из показателей эффективности системы ПОД/ФТ выступает чистый отток капитала.

В соответствии со сложившейся российской системой оценки Банк России ежемесячно публикует статистические данные по такому показателю, как сальдо финансовых операций частного сектора, который до 2018 года носил название чистого вывоза капитала частным сектором. В свою очередь, согласно «Исследованию оттока капитала из РФ: от мифов к реальности» [17], проведённому экспертами Российского фонда прямых инвестиций (РФПИ), Центра национального интеллектуального резерва при МГУ и компании Ernst\&Young, данный показатель отнюдь не является идентичным показателю чистого оттока капитала из страны. По мнению экспертов, целесообразно оперировать показателем Private Capital Flows (PCF), рассчитываемым Всемирным Банком. В связи с чем, при проведении данного исследования была проанализирована статистика по РСF. Так как на сайте Всемирного Банка [23] 
отсутствуют итоговые данные по показателю РСF, при проведении расчётов была применена следующая формула:

Private Capital Flows $=$ Foreign Direct Investment + Portfolio Investment где:

Foreign Direct Investment (FDI) - это прямые иностранные инвестиции,

Portfolio Investment (PI) - это портфельные инвестиции.

Также согласно результатам исследования Ernst\&Young необходимо проводить сравнение оттока капитала из России с показателями таких стран, как Норвегия, Кувейт и Япония. В связи сравнивались значения показателя чистого оттока капитала в США, Норвегии, Кувейте, Японии и России в рамках анализа эффективности систем финансового мониторинга. Для этого были взяты данные по чистым потокам прямых и портфельных инвестиций, а также по производным финансовым инструментам и прочим инвестициям, а суммарное значение этих показателей было выражено в процентах к ВВП каждой страны. Полученные результаты представлены на рисунке 1.

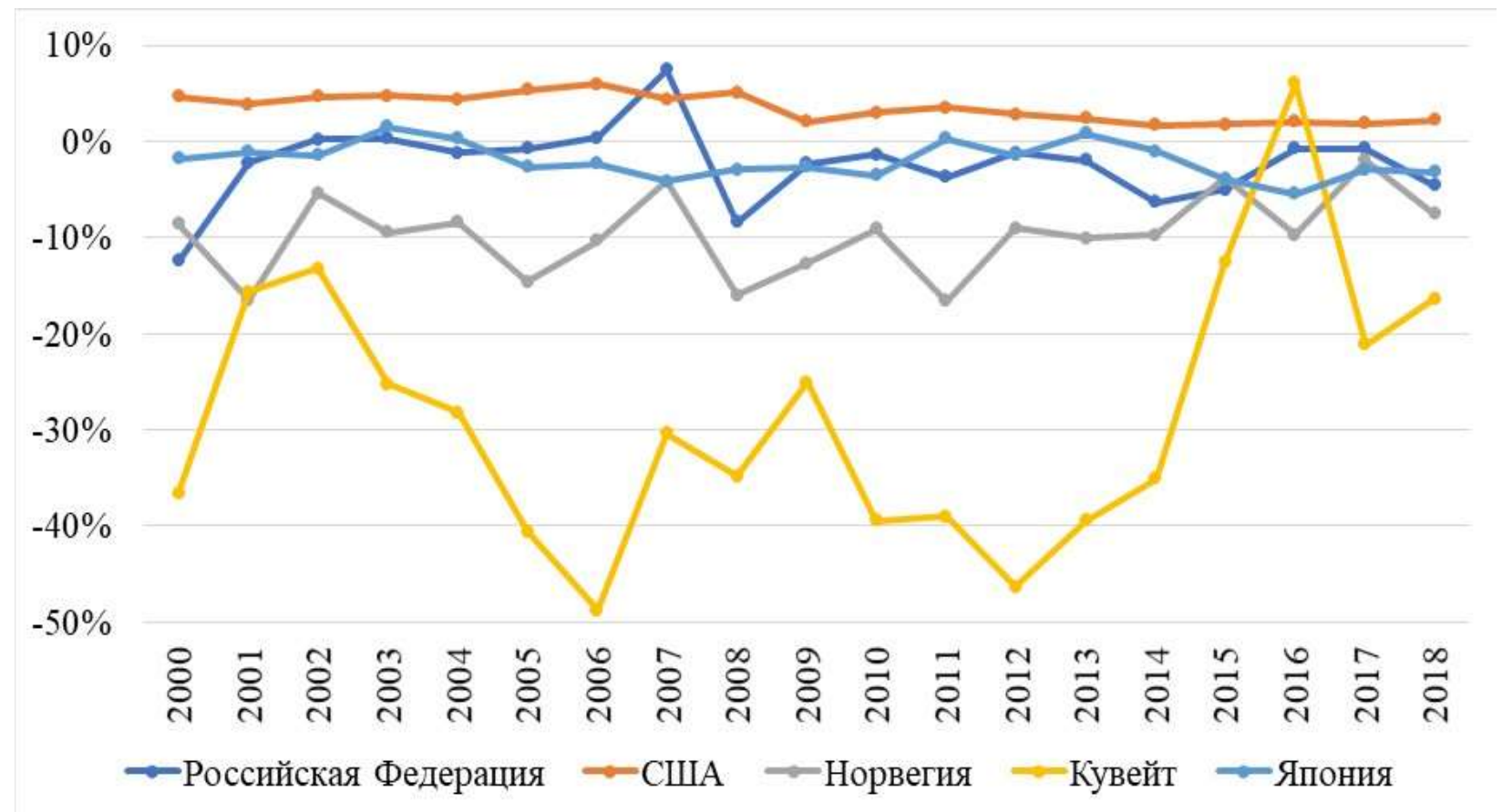

\section{Рис. 1. Чистый приток/отток капитала за 2000-2018 гг., \% ВВП}

Согласно Рисунку 1 наиболее стабильным является процентный показатель чистого притока/оттока капитала в США и Японии. В Кувейте мы наблюдаем скачкообразную динамику. В России же динамика менее стабильна, чем в США и в Японии, однако значительно лучше, чем в Норвегии и в Кувейте. Тем не менее, именно процент чистого притока/оттока капитала от 
ВВП в России и в Кувейте имеет положительную динамику в долгосрочной перспективе, в то время как в США и в Японии тот же показатель имеет нисходящую динамику, а в Норвегии значение чистого оттока капитала в 2000 году и 2018 году практически не изменилось $(-8,65 \%$ и $-7,53 \%$ от ВВП соответственно). Таким образом, наиболее стабильными являются американская и японская системы финансового мониторинга, однако наиболее эффективными с точки зрения снижения чистого оттока капитала являются российская и кувейтская системы.

Однако для точной оценки эффективности систем финансового мониторинга различных стран сравнение одного показателя чистого оттока капитала недостаточно. В связи с чем в рамках исследования были сравнены результаты, полученные экспертами ФАТФ при проведении оценки эффективности национальных систем финансового мониторинга. Ввиду наличия развёрнутой оценки эффективности лишь по некоторым странам, в рамках исследования были изучены такие страны, как США, Норвегия, Великобритания и Китай: был проведён сравнительный анализ результатов оценки по эти странам как их между собой, так и с оценками российской системы ПОД/ФТ. Подученные результаты представлены в таблице 1.

Таблица 1

Сравнительный анализ оценок эффективности национальных систем финансового мониторинга по ФАТФ

\begin{tabular}{|c|c|c|c|c|c|c|c|c|c|c|}
\hline Критерий & $\begin{array}{c}\text { США } \\
(2016)\end{array}$ & $\begin{array}{c}\text { Норвегия } \\
(2019)\end{array}$ & \multicolumn{2}{c|}{$\begin{array}{c}\text { Великобритания } \\
(2018)\end{array}$} & \multicolumn{2}{c|}{$\begin{array}{c}\text { Китай } \\
(2019)\end{array}$} & $\begin{array}{c}\text { Россия } \\
(2019)\end{array}$ \\
\hline IO.1 & $\mathrm{SE}$ & 2 & $\mathrm{SE}$ & 2 & $\mathrm{HE}$ & 3 & $\mathrm{SE}$ & 2 & $\mathrm{SE}$ & 2 \\
\hline $\mathrm{IO} .2$ & $\mathrm{SE}$ & 2 & $\mathrm{SE}$ & 2 & $\mathrm{SE}$ & 2 & $\mathrm{ME}$ & 1 & $\mathrm{SE}$ & 2 \\
\hline $\mathrm{IO} .3$ & $\mathrm{ME}$ & 1 & $\mathrm{ME}$ & 1 & $\mathrm{ME}$ & 1 & $\mathrm{ME}$ & 1 & $\mathrm{ME}$ & 1 \\
\hline $\mathrm{IO} .4$ & $\mathrm{ME}$ & 1 & $\mathrm{ME}$ & 1 & $\mathrm{ME}$ & 1 & $\mathrm{LE}$ & 0 & $\mathrm{ME}$ & 1 \\
\hline $\mathrm{IO} .5$ & $\mathrm{LE}$ & 0 & $\mathrm{ME}$ & 1 & $\mathrm{SE}$ & 2 & $\mathrm{LE}$ & 0 & $\mathrm{SE}$ & 2 \\
\hline $\mathrm{IO} .6$ & $\mathrm{SE}$ & 2 & $\mathrm{SE}$ & 2 & $\mathrm{ME}$ & 1 & $\mathrm{ME}$ & 1 & $\mathrm{HE}$ & 3 \\
\hline $\mathrm{IO} .7$ & $\mathrm{SE}$ & 2 & $\mathrm{ME}$ & 1 & $\mathrm{SE}$ & 2 & $\mathrm{ME}$ & 1 & $\mathrm{ME}$ & 1 \\
\hline $\mathrm{IO} .8$ & $\mathrm{HE}$ & 3 & $\mathrm{ME}$ & 1 & $\mathrm{SE}$ & 2 & $\mathrm{SE}$ & 2 & $\mathrm{SE}$ & 2 \\
\hline IO.9 & $\mathrm{HE}$ & 3 & $\mathrm{SE}$ & 2 & $\mathrm{HE}$ & 3 & $\mathrm{SE}$ & 2 & $\mathrm{HE}$ & 3 \\
\hline IО.10 & $\mathrm{HE}$ & 3 & $\mathrm{ME}$ & 1 & $\mathrm{HE}$ & 3 & $\mathrm{LE}$ & 0 & $\mathrm{ME}$ & 1 \\
\hline О.11 & $\mathrm{HE}$ & 3 & $\mathrm{SE}$ & 2 & $\mathrm{HE}$ & 3 & $\mathrm{LE}$ & 0 & $\mathrm{ME}$ & 1 \\
\hline Общий балл & - & 22 & - & 16 & - & 23 & - & 10 & - & 19 \\
\hline Средний рейтинг & $\mathrm{SE}$ & 2 & $\mathrm{ME}$ & 1 & $\mathrm{SE}$ & 2 & $\mathrm{LE}$ & 0 & $\mathrm{ME}$ & 1 \\
\hline
\end{tabular}

Примечание: HE - высокая, SE - значительная, ME - умеренная, LE низкая степень эффективности системы финансового мониторинга. 
Из Таблицы 1 видно, что согласно методологии ФАТФ существует 11 критериев для оценки эффективности систем финансового мониторинга:

$>$ IO.1 - Риски, политика и координация;

$>$ IO.2 - Международное сотрудничество;

$>$ IO.3 - Надзор;

$>$ IO.4 - Профилактические меры;

$>$ IO.5 - Юридические лица и договорённости;

$>$ IO.6 - Финансовая разведка;

$>$ IO.7 - Расследование и судебное преследование отмывания денег;

$>$ IO.8 - Конфискация;

$>$ IO.9 - Расследование и судебное преследование финансирования терроризма;

$>$ IO.10 - Превентивные меры и финансовые санкции за ФТ;

$>$ IO.11 - Финансовые санкции за распространение оружия массового поражения (ОМП).

Согласно проведённому анализу, страной с самой неэффективной системой финансового мониторинга является Китай (общий балл - 10 , средний рейтинг - «низкий»). Наибольший балл эффективности («значительный») набирает Великобритания (23 балла) и США (22 балла). В то время как в Норвегии и в России выявлена умеренная степень эффективности систем финансового мониторинга (16 и 19 баллов соответственно).

Закономерно возникает вопрос: за счёт каких критериев каждая из стран преуспевает в степени эффективности системы финансового мониторинга, а за счёт каких наоборот отстаёт? Иначе говоря, в чём заключаются преимущества и недостатки каждой из рассматриваемых систем финансового мониторинга согласно оценкам ФАТФ. Для этого проведём критериальный анализ оценок.

В США согласно данным ФАТФ выявлена высокая степень эффективности системы финансового мониторинга в рамках:

- конфискации доходов и иных средств совершения преступлений;

- полноты и глубины расследований ФТ, степени преследования и наличия эффективных, соразмерных и сдерживающих санкций;

- степени эффективности выявления и воспрепятствования в сборе, перемещении и использовании денежных средств в рамках ФТ и ОМП, а также в злоумышленном использовании некоммерческих организаций.

Во-первых, по оценкам экспертов в США прекрасно выстроена система конфискации. Она отличается своей эффективностью за счёт использования таких видов конфискации, как административная, без вынесения приговора и 
криминальная. Кроме того, федеральными властями регулярно проводится конфискация ценных бумаг. Отметим, что в США компетентные органы могут проводить конфискацию активов в контексте крупных и сложных дел, а также в отношении активов, находящихся как внутри страны, так и за рубежом.

Во-вторых, в США выстроена надёжная правовая база для борьбы с ФТ, а также существует чёткое и всестороннее понимание терроризма и рисков ФТ. Все усилия в рамках расследований ФТ полностью интегрированы в общую стратегию борьбы с терроризмом, в связи с чем любое расследование, связанное с терроризмом, сопровождается параллельным расследованием с целью выявления потенциальных источников финансовой поддержки. Кроме того, в США активно расследуются, преследуются в судебном порядке и осуждаются лица, вовлечённые в широкий спектр схем ФТ, за счёт реализации законодательства, которое охватывает любую форму материальной поддержки.

Во-вторых, в США развиты превентивные меры в отношении ФТ: разработаны и применяются всеобъемлющие механизмы обмена оперативной информацией между местными и аналитическими подразделениями. Власти США также активно взаимодействуют с частным сектором, обеспечивая конструктивный обмен информацией о терроризме и угрозах терроризма. Кроме того, Управление по контролю за иностранными активами регулярно публикует черный список лиц, который используется тысячами финансовых организаций в США и во всём мире для проверки транзакций и счетов в реальном времени. Более того, широкий спектр санкций отражает масштабы, сложность и международный охват финансовой системы США.

При этом чуть ниже оценена эффективность по следующим параметрам:

- степень идентификации, оценки и понимания рисков ОД/ФТ, координации мероприятий по снижению этих рисков;

- степень обеспечения и предоставления конструктивной и своевременной информации, оперативных финансовых данных, доказательств и помощи в рамках международного сотрудничества;

- степень эффективности использования компетентными органами финансовых данных в целях проведения финансовых расследований ОД/ФТ;

- полнота и глубина расследований ОД, степень преследования и наличие эффективных, соразмерных и сдерживающих санкций.

Во-первых, эксперты ФАТФ отмечают, что в целом в США достигнут значительный уровень понимания своих рисков посредством комплексных и постоянных процессов их оценки. Кроме того, в США особенно хорошо 
развита политика и оперативная координация в рамках борьбы с терроризмом и связанных с этим вопросов финансирования, которые являются приоритетными областями национальной безопасности. Тем не менее, в нормативно-правовой базе существуют пробелы, которые могут повлиять на степень проработанности рисков. Например, адвокаты, бухгалтеры и агенты по недвижимости не подпадают под действие комплексных мер в рамках ПОД/ФТ.

Во-вторых, в США действует эффективная система международного сотрудничества. Являясь одной из крупнейших экономик и финансовых систем в мире, США является получателем очень большого количества запросов, связанных с финансовыми преступлениями. Отзывы, полученные от других стран, не выявили каких-либо систематических проблем и поддержали мнение о том, что США обеспечивают хорошее качество и конструктивность взаимной правовой помощи, в том числе в отношении ОД/ФТ и конфискации активов. Тем не менее, существуют проблемы в рамках предоставления информации о бенефициарных владельцах. Отсутствие легкодоступной информации означает, что власти США вряд ли проведут ресурсоёмкое расследование с целью раскрытия информации по запросу иностранного государства, если только дело не имеет достаточно высокого приоритета. Однако даже в этом случае своевременный доступ к информации не может быть гарантирован.

В-третьих, в США отмечен прямой доступ у компетентных органов к финансовой информации, которая включает в себя отчёты о подозрительных операциях и иные обязательные финансовые документы. Кроме того, постоянно развиваются сложные автоматизированные бизнес-правила для определения приоритетов поступающих финансовых документов, что способствует повышению оперативности в анализе данных. Тем не менее, существует возможность развить и расширить полномочия по сбору финансовой информации в целях повышения эффективности расследований.

В-четвёртых, в США проводится большое количество финансовых расследований в рамках ОД, в результате которых ежегодно выносится в среднем более 1200 приговоров на федеральном уровне. Осуществляется широкий спектр деятельности по противодействию ОД, а также особое внимание уделяется серьёзным, сложным и дорогостоящим уголовным преступлениям. Кроме того, межучережденческие целевые группы объединяют дополнительные экспертные знания и ресурсы для конкретных учреждений, что облегчает проведение сложных финансовых расследований. Тем не менее, на 
уровне штатов отсутствует единый подход в сборе и анализе информации, что приводит к не уделению должного внимания местными органами вопросам ОД.

Однако, к сожалению, экспертами ФАТФ был проставлена умеренная степень эффективности системы надзора и профилактических мер. Более того, была дана низкая оценка степени эффективности законодательства в отношении юридических лиц и договорённостей. Что в совокупности занизило рейтинг эффективности национальной системы финансового мониторинга.

По оценкам экспертов ФАТФ в США сложная система надзора: на федеральном уровне и уровне штатов существует несколько регулирующих органов, которые применяют различные подходы в надзорной деятельности. Кроме того, под действие превентивных мер попадают казино и организации, связанные с покупкой-продажей драгоценных металлов и камней, адвокаты, бухгалтеры, поставщики услуг, агенты по недвижимости. Тем не менее, в случае если казино и дилерам драгметаллов и драг. камней уделено пристальное внимание, то в отношении агентов по сделкам с элитной недвижимостью, а также в отношении адвокатов и бухгалтеров существуют определённые пробелы в законодательстве. Следовательно, существующая система надзора и профилактические меры не обеспечивают адекватного устранения уязвимостей ОД/ФТ и требуют дополнительной проработки.

Самый низкий уровень эффективности в США наблюдается относительно законодательства по юридическим лицам и договорённостям. Важно отметить, что в целом меры по предотвращению неправомерного использования юридических лиц являются неадекватными. Правовая база США имеет серьёзные пробелы, которые препятствуют эффективности в этой области. В частности, при проведении оценки экспертами ФАТФ было подчёркнуто отсутствие требований на законодательном уровне для систематической регистрации информации о бенефициарных владельцах (что является одним из требований ФАТФ). В связи с чем способность компетентных органов своевременно получать данную информацию ставится под сомнение, так как правоохранительные органы США часто вынуждены прибегать к ресурсоёмким и трудоёмким методам расследования и наблюдения.

Таким образом, в США в среднем наблюдается значительная степень эффективности системы финансового мониторинга. В стране практически идеально выстроена система конфискации активов, сформирована надёжная правовая база для борьбы с ФТ, а также прекрасно развиты превентивные меры. Тем не менее, необходимо в первую очередь расширить круг лиц, в отношении 
которых действует существующий комплекс мер в рамках ПОД/ФТ, в который обязательно должны быть включены адвокаты, бухгалтеры и агенты по недвижимости. Кроме того, необходимо сделать легкодоступной информацию о бенефициарных владельцах и единообразить подход к сбору и анализу информации в рамках ПОД.

В отличие от США в Норвегии система финансового мониторинга не удостоена высокой оценки ни по одному из критериев. При этом 6 из 11 показателей оценены как умеренно эффективные, а оставшиеся - как значительно эффективные. Изучим каждую из оценок более подробно.

По оценкам экспертов ФАТФ в Норвегии на значительном уровне эффективности находится понимание рисков и международное сотрудничество, которое является сильной чертой системы ПОД/ФТ в стране. Также в Норвегии разработана национальная стратегия в рамках ПОД/ФТ и развита координация. Тем не менее, существуют серьёзные недостатки в отношении конфискации активов и взаимной правовой помощи. Более того, Норвегии необходимо углубить анализ рисков, связанных с ОД, и сопоставить уязвимости конкретных секторов, усилить внимание к более сложным схемам ОД и улучшить использование количественных данных. Кроме того, необходимо рассмотреть возможность привлечения крупных банков, международных организаций, предоставляющих услуги по переводу денег или ценностей, и крупных игорных структур при подготовке к будущей оценке рисков. А также переориентировать принимаемые меры на более широкие приоритеты.

Помимо первых двух критериев эксперты ФАТФ достаточно высоко оценили степень эффективности финансовой разведки со стороны Национальной службы уголовного розыска и полицейских округов. Также было отмечено, что в Норвегии создан механизм для общения и координации по вопросам распространения ОМП и развит процесс расследования в рамках ФТ. Однако, Норвегия не полностью осуществила мониторинг всех подотчётных лиц на предмет соответствия требованиям ПОД/ФТ, в связи с чем существует необходимость в создании более чётких отраслевых указаний со стороны надзорных органов в отношении этих лиц.

Стоит отметить, что в Норвегии создана система надзора, которая должна позволить в будущем осуществлять более детальный надзор в рамках ПОД/ФТ. Однако эта система находится на ранней стадии разработки, в связи с чем лишь предполагает более частое проведение специализированных проверок банков с 
более высокими рисками, а также наложение административных санкций. Будет ли эта система надзора эффективной на данный момент не известно.

Однако в Норвегии до сих пор отсутствует какая-либо количественная информация относительно использования временных мер для обеспечения безопасности активов до их конфискации, поскольку эта информация до сих пор не отслеживается. Несмотря на предоставленную налоговыми органами информацию о количестве дел и суммах, которые должны быть возмещены в отношении переоценённых налогов и наложенных штрафов, отсутствует возможность получения какой-либо информации о суммах, фактически возмещённых в соответствии с соответствующими приказами, поскольку эта информация не отслеживается отдельно от регулярного сбора налогов. Кроме того, предоставленная информация не может быть разбита на основные и иностранные преступления, а также отсутствуют статистические данные о количестве дел и размере доходов от преступлений, переданных иностранным юрисдикциям или репатриированных в них.

Таким образом, можно сказать, что в Норвегии ещё только зарождается эффективная система финансового мониторинга. С последней национальной оценки рисков от 2014 года Норвегия существенно улучшила ряд показателей, однако больше половины из них остаются ещё на достаточно невысоком уровне. Основным пробелом, который стране предстоит устранить в ближайшем будущем, является полнота и качество статистических данных в отношении оценки эффективности проводимых надзорных мероприятий, превентивных мер и финансовых санкций в рамках ПОД/ФТ.

В Великобритании ситуация обстоит лучше, чем в Норвегии и США: ни по одному из критериев не получена низкая оценка эффективности, а по 4 из 11 показателей выставлен высокий балл. Разберём оценки по каждому критерию.

По мнению экспертов ФАТФ Великобритания отлично понимает риски в рамках ОД/ФТ. Национальные стратегии и мероприятия в сфере ПОД/ФТ направлены на устранение рисков, указанных в национальной оценке риска. Кроме того, за последние годы в Великобритании были введены новые инструменты и полномочия по расследованию ОД/ФТ. Объединённая оперативная группа по разведке и борьбе с отмыванием денег стала непосредственным участником обмена информацией между государственным и частным сектором. Более того, произошли значительные улучшения в отношении координации на оперативном уровне между правоохранительными органами во всех юрисдикциях в Великобритании. 
В дополнение Великобритания активно и систематически расследует ФТ наряду с другими расследованиями. Исследования ФАТФ показали, что в Великобритании преследуется целый ряд видов деятельности ФТ и что ФТ выделена как отдельная преступная деятельность. Более того, расследования ФТ хорошо интегрированы в более широкие стратегии борьбы с терроризмом, а агентства отлично координируют и сотрудничают между юрисдикциями, регионами и секторами. Отметим, что органы по борьбе с ФТ поддерживают тесные и плодотворные отношения как с финансовыми учреждениями, так и с сектором некоммерческих организаций. Все обвинительные приговоры в рамках ФТ сводятся к тюремному заключению. Таким образом, Великобритания продемонстрировала свою способность и готовность использовать все доступные меры для разрушения ФТ, включая замораживание, арест и конфискацию, а также отмену законных льгот и пособий, постановлений об ограничении деятельности и передвижений.

На таком же высоком уровне в Великобритании представлена система борьбы с распространением оружия массового поражения. Противодействие финансированию распространения ОМП является стратегическим приоритетом для Великобритании, в связи с чем на законодательном уровне принят ряд мер для устранения пробелов в существующей системе ЕС. В то числе создано Управление исполнения финансовых санкций для повышения внимания к вопросам распространения ОМП. Информационно-пропагандистская деятельность данного Управления позволила финансовым учреждениям лучше понять свои обязательства по внедрению системы адресных финансовых санкций, особенно в банковском секторе, где наиболее вероятно выявление активов, связанных с распространением ОМП.

Однако более низкий уровень эффективности - значительный присуждён экспертами ФАТФ в отношении международного сотрудничества, юридических лиц и договорённостей, расследования ОД и конфискации активов.

В целом Великобритания предоставляет широкий спектр конструктивной взаимной правовой помощи и выдачи. Неформальное сотрудничество между правоохранительными органами и прокуратурой осуществляется через обширную зарубежную сеть уголовного правосудия, в которую входят сотрудники разведки, следователи и прокуроры. Другой сильной особенностью британской системы является обмен публичной и частной информацией через в рамках проекта JMLIT, в который иностранные партнёры могут направлять 
свои запросы на рассмотрение. Тем не менее, формальное международное сотрудничество могло бы выиграть от лучшей координации запросов, направляемых через Центральное управление Министерства внутренних дел Великобритании в целях обеспечения своевременной помощи. Ограничения в рамках Отдела финансовой разведки Великобритании влияют на его способность обеспечивать сотрудничество и объём помощи на должном уровне.

Кроме того, Великобритания выступила в качестве глобального лидера в области бенефициарного права, содействуя использованию публичных реестров и используя различные форумы для поощрения прозрачности в этой области. Великобритания прекрасно понимает риски ОД/ФТ, связанные с юридическими лицами и соглашениями. Однако этого не происходит в отношении компаний, которые ведут счета за рубежом. В этом случае доступ к реестру в режиме онлайн является быстрым и легким, однако информация подлежит исключительно базовым проверкам и остаётся в значительной степени непроверенной.

В отношении ОД Великобритания регулярно проводит расследования. Ежегодно проводится более 2000 судебных преследований и выдвигается более 1400 обвинительных приговоров в отношении самостоятельных случаев ОД или случаев, когда ОД было основным преступлением. Все соответствующие правоохранительные органы отдают приоритет ОД и финансовым расследованиям, в том числе на региональном и местном уровне. Инструменты расследования и способы обмена информацией надёжны, а ресурсы гибко применяются как внутри, так и между правоохранительными органами для удовлетворения потребностей следствия. Однако, поскольку случаи ОД сложны и, как правило, для их завершения требуются годы, а статистика в этой области не является исчерпывающей, Великобритания пока не может претендовать на высокую оценку эффективности расследований ОД. Такое же замечание сделано экспертами ФАТФ в отношении британской системы конфискации.

Что же касается британской системы надзора, профилактических мер и финансовой разведки, то эксперты ФАТФ оценили степень их эффективности как умеренную. Было отмечено, что Великобритании необходимо обеспечить надлежащую интенсивность надзора для всех категорий лиц и организаций (как с минимальным, так и с высоким риском). В рамках существующих программ систематического и упреждающего надзора значительное число фирм, 
осуществляющих деятельность с высоким и средним риском, выходит за рамки регулярного и циклического надзора. Кроме того, ввиду того, что в Великобритании представлен чрезвычайно большой и разнообразный финансовый сектор экономики, зачастую превентивные меры не охватывают должный спектр организаций. В связи с чем соответствие ПОД/ФТ не одинаково для разных категорий финансовых учреждений. Более того, Отдел финансовой разведки Великобритании страдает от недостатка доступных ресурсов (человеческих и информационных) и аналитических возможностей, что вызывает серьёзную обеспокоенность. Следует отметить, что эта проблема была известна британским властям более 10 лет назад, но до сих она никак не решена, кроме как ограничением роли соответствующего отдела. В свою очередь подобное решение властей ставит под сомнение качество финансовой разведки.

Таким образом, несмотря на такие преимущества системы финансового мониторинга, как развитая система расследования ФТ и успешно применяемые меры по борьбе с распространением ОМП, в Великобритании сильно страдает система надзора, профилактики и финансовой разведки. Иными словами, делая серьёзный акцент в отношении одних направлений деятельности компетентных органов, власти Великобритании закрывают глаза на наличие серьёзных пробелов в законодательстве относительно других направлений ПОД/ФТ, что приводит к более низкому среднему уровню эффективности системы в целом.

В сравнении с уже рассмотренными зарубежными системами финансового мониторинга в Китае зафиксирован самый низкий уровень эффективности. По четырём критериям экспертами ФАТФ выставлен самый низкий балл. И лишь по трём критериям степень эффективности является значительной.

По результатам исследования ФАТФ власти Китая продемонстрировали чёткое понимание содержания национальной оценки риска. Тем не менее, ввиду своеобразной направленности деятельности правоохранительных органов, совершенно отсутствует внимание тем случаям, которые не связаны непосредственно с самим преступлением. Однако Китай демонстрирует активное сотрудничество и координацию на политическом и законодательном уровнях. В связи с чем по первому критерию китайской системе финансового мониторинга присвоен значительный уровень эффективности.

Высоко оценена также система конфискации активов. В Китае преследование преступных доходов является основной целью политики. 
Конфискация средств, в том числе преступных доходов, реализуется обычно в процессе вынесения приговора. Необходимо отметить, что у Китая в отличие от других стран реализована возможность конфисковать имущество даже в тех случаях, когда преступник скрылся из страны или умер.

Однако, в Китае в рамках реализации расследований ФТ в отношении ФТ выявлено три основных недостатка, связанных с охватом требований к организациям, типами активов и средств, которые на практике могут быть заморожены, типом операций, которые могут быть запрещены, и отсутствием оперативного осуществления расследований и санкций за пределами страны. В связи с чем Китаю необходимо создать всеобъемлющую правовую базу для реализации расследований, связанной с ОД/ФТ, которая будет включать меры запрета, распространяться на все активы определённых субъектов и применяться безотлагательно в отношении назначений Совета Безопасности ООН. В то же время необходимо устранить временные задержки при замораживании активов.

Умеренный уровень эффективности был присвоен экспертами ФАТФ в отношении международного сотрудничества, системы надзора, финансовой разведки и расследований ОД. Эксперты отмечают сложность процедуры обеспечения запроса, которая соответствует китайскому законодательству и в свою очередь приводит к очень длительному процессу, хотя в особых случаях сроки могут быть сокращены. Тем не менее, отзывы стран о степени эффективности сотрудничества со стороны Китая неоднозначны.

В отношении системы надзора выявлены недостатки в большинстве регулируемых секторов, в частности, период проверки судимости не должен превышать трёх лет. Кроме того, система надзора в рамках ПОД/ФТ в Китае в значительной степени ориентирована на финансовый сектор. Также существуют несоответствия в подходах, используемых отраслевыми надзорными органами.

Финансовая разведка реализуется правоохранительными органами в Китае на федеральном, региональном и местном уровне. Однако полученная информация используется в основном для выявления и отслеживания доходов, а также для поддержки расследований и судебного преследования за основные правонарушения и лишь в ограниченном объёме для целей ПОД. Таким образом, всё внимание китайских правоохранительных органов направлено на обычные правонарушения внутри страны, а не на более широкую поддержку самостоятельных расследований ОД/ФТ. Тем самым использование 
финансовой разведки правоохранительными органами ведёт к разрушению криминальных сетей, но не приводит к адекватной идентификации операцийОД.

На самом низком уровне в Китае развиты профилактические меры, законодательство в отношении юридических лиц и договорённостей, а также превентивные финансовые меры и методы борьбы с распространением ОМП. Так экспертами ФАТФ выявлено у финансовых организаций недостаточное понимание рисков ОД/ФТ, в связи с чем применяемые меры не соответствуют этим рискам. Институты онлайн-кредитования также не имеют понимания рисков ОД/ФТ и своих обязанностей в рамках ПОД/ФТ. Отчёты о подозрительных транзакциях со стороны финансового сектора экономики практически отсутствуют. Всё это усугубляется отсутствием в стране детального понимания рисков ОД/ФТ в отношении каждого типа юридических лиц, а также возможностью обхода юридическими лицами процедуры регистрации.

Таким образом, Китай, являясь самым большим по объёмам поставщиком товаров в другие страны, оказался не способным эффективно организовать финансовый мониторинг в рамках ПОД/ФТ на национальном уровне. Как итог ежегодно из Китая поступает большое количество незаконных доходов, в том числе полученных в результате незаконного сбора средств, мошенничества, незаконного оборота наркотиков, коррупции и взяточничества, налоговых преступлений, подделки продуктов и незаконных азартных игр.

В России согласно оценкам экспертов ФАТФ на высоком уровне развита финансовая разведка и расследование ФТ. Российские правоохранительные органы регулярно и эффективно получают доступ и используют данные финансовой разведки и другую соответствующую информацию для сбора доказательств в рамках расследования ОД/ФТ. Прокуроры также обеспечивают использование имеющейся информации при разработке дел и систематически проверяют тот факт, что все финансовые аспекты расследуемого дела изучены. Более того, в России существует надёжная правовая база для борьбы с ФТ, которая в высокой степени соответствует международным стандартам.

Также, по мнению экспертов ФАТФ, российские власти на достаточно хорошем уровне понимают имеющиеся в стране риски ОД/ФТ. Выявленные риски ОД являются всеобъемлющими и разумными, а риски ФТ хорошо определены и поняты. В целом национальная политика ПОД/ФТ надлежащим образом учитывает выявленные риски ОД/ФТ. Внутренняя координация и сотрудничество являются основным преимуществом российской системы. 
Более того, по большинству отзывов зарубежных стран Россия оказывает взаимную правовую помощь конструктивным и своевременным образом, в том числе оперативно выполняя запросы об экстрадиции. Подобный уровень достигается правильной расставкой приоритетов в срочности ответов, указанной заявителем, в соответствии запроса рискам, указанным в национальной оценке рисков ОД/ФТ, а также в наличии правовых ограничений для задержания лиц. Кроме того, электронная система управления делами в рамках групповой политики помогает контролировать выполнение всех входящих запросов.

Не менее важным является наличие эффективных механизмов, которые значительно снижают злоупотребление использования юридических лиц в схемах ОД/ФТ. В частности, существуют строгие правила регистрации, помимо которых власти постоянно усиливают меры по выявлению неточной информации и неактивных компаний. В результате точность реестра компаний достаточно высока, а информация более полезна. Также необходимо отметить, что между Федеральной налоговой службой и Росфинмониторингом, а также правоохранительными органами налажено сотрудничество на хорошем уровне в рамках следственной деятельности, что приводит к увеличения количества административных и уголовных санкций, которые в свою очередь способствуют снижению привлекательности юридических лиц для преступников.

Сложнее обстоит дело с конфискацией. В России конфискация, касающаяся ложных или не декларированных движений валюты и оборотных инструментов на предъявителя, осуществляется в меньшей степени, отчасти изза отсутствия обязательства декларирования в рамках Евразийского экономического союза. Принимая во внимание обширные сухопутные границы России и другие соответствующие риски, конфискуется относительно низкий процент выявленных контрабандных денег. Однако выявленные контрабандные преступления и наложенные штрафы в результате частично компенсируют эти такой низкий процент конфискации. Также для России представляет угрозу неправомерное использование виртуальных активов, особенно в связи с незаконным оборотом наркотиков и преступностью через Интернет. Проблема состоит в том, что компетентные органы могут конфисковать виртуальные активы только после того, как они будут обменены на реальные активы. Тем не менее, эксперты ФАТФ поставили значительный уровень эффективности системы конфискации активов и иных средств. 
Наименьшего рейтинга (умеренный уровень эффективности) в сравнении другими показателями удостоилась система надзора, профилактические меры, расследование ОД, превентивные меры и финансовые санкции в отношении ФТ, а также меры по борьбе с распространением ОМП.

Российский банковский сектор подвергается высокому уровню угрозы со стороны преступников. С 2013 года количество кредитных организаций, лицензированных в России, сократилось вдвое из-за слияний и отзыва многих лицензий (в том числе ввиду серьёзных нарушении в рамках ПОД/ФТ). Тем не менее, лишь немногие из запланированных целевых проверок, сфокусированных исключительно на ПОД/ФТ, были проведены. В связи с чем эксперты ФАТФ были обеспокоены тем, что проводится недостаточное количество инспекций в рамках ПОД/ФТ. Кроме того, эксперты считают, что текущая модель надзора Банка России чрезмерно опирается на дистанционные формы, а денежные штрафы за нарушения ПОД/ФТ занижены в сравнении с другими странами.

Превентивные меры в отношении ОД/ФТ в России находятся на недостаточно высоком уровне, так как у некоторых представителей установленных нефинансовых предприятий и профессий (далее - УНФПП) наблюдается хорошее понимание существующих рисков (например, у бухгалтеров и аудиторов), а у других - менее глубокое (казино, агенты по недвижимости) или поверхностное (адвокаты и нотариусы). При этом уровень понимания рисков дилерами драгметаллов и камней не может считаться соответствующим тем рискам, которые были выявлены в ходе национальной оценки рисков ОД. Кроме того, несмотря на то, что УНФПП знают о своих обязанностях по направлению сообщений о подозрительных операциях, лишь некоторые направляют их в достаточном количестве.

В России в целом успешно выявляются случаи ОД за счёт проведения финансовых расследований. При выявлении такой деятельности компетентные органы начинают расследование ОД более чем в 91\% случаев, большинство из которых завершается выдвижением обвинений. Однако объём проводимых расследований ОД лишь частично соответствует существующим в стране рискам, так как почти 85\% всех выявляемых преступлений в рамках ОД связаны с наркопреступлениями, а также использованием и хищением бюджетных средств. Что же касается взяточничества, то количество уголовных и судебных расследований в рамках ОД не совсем соответствует существующим рискам. 
Также в России имеется надлежащая система, позволяющая применять целевые финансовые санкции. Однако в некоторых областях имеются существенные пробелы. В первую очередь это относится к безотлагательному применению финансовых санкций, а также к отсутствию чётких требований, распространяющихся на все физические и юридические лиц. В связи с чем несмотря на то, что в России общий уровень риска ФТ определён как низкий, некоторые сегменты риска были оценены экспертами ФАТФ как подверженные среднему риску и подлежащие дополнительному контролю.

\section{Меры по повышению эффективности российской системы ПОД/ФТ}

Таким образом, изучив преимущества и недостатки российской системы финансового мониторинга в рамках анализа оценки эффективности системы экспертами ФАТФ, а также предварительно проанализировав плюсы и минусы зарубежных систем финансового мониторинга на примере США, Норвегии, Великобритании и Китая, в рамках исследования были предложены следующие меры по повышению эффективности российской системы ПОД/ФТ.

В первую очередь необходимо:

- усовершенствовать систему надзора: необходимо планировать достаточное количество проверок в рамках ПОД/ФТ, а также чаще проводить внеплановые проверки в случае необходимости.

- усовершенствовать систему превентивных мер: обеспечить проведение УНФПП регулярной переоценки рисков в рамках ПОД/ФТ; обеспечить своевременную и регулярную отправку представителями УНФПП достаточного количества сообщений о подозрительных операциях.

- усовершенствовать систему расследования ОД: сделать больший акцент на расследовании сложных схем ОД, а также в области коррупции; принять закон о признании виртуальных активов в качестве имущества.

- усовершенствовать применение превентивных мер в отношении ФТ и целевых финансовых санкций: обеспечить безотлагательное применение целевых финансовых санкций в отношении субъектов ФТ; обязать замораживать активы и не предоставлять иные средства в интересах лиц или организаций, включённых в чёрные списки.

- усовершенствовать меры борьбы с распространением ОМП:

Во вторую очередь необходимо:

- улучшить понимание рисков, политику и координацию: провести систематический и глубокий стратегический анализ финансовых потоков, 
которые могут быть связаны с организованной преступностью в целом и с ей транснациональными аспектами, охватив весь спектр ОД/ФТ.

- повысить уровень международного сотрудничества: применять режим конфискации активов в рамках обработки международных запросов; расширить список количественных параметров предоставления информации в рамках международного сотрудничества.

- усовершенствовать систему в отношении юридических лиц и договорённостей: провести разъяснительные беседы с субъектами первичного финансового мониторинга с целью уточнения понятия бенефициарных собственников и обеспечить жёсткое соблюдение ими требований в отношении юридических лиц, находящихся во владении или под контролем субъектов, попадающих под санкции.

- усовершенствовать систему конфискации: объединить в один законы по конфискации доходов, содержащиеся в уголовном и уголовнопроцессуальном кодексах; создать фонд, в который будут поступать все конфискованные активы, с целью упрощения отслеживания полноты возмещённого ущерба потерпевшим, а также ускорения самого процесса; применять систему конфискации рамках запросов о международной помощи.

После проведения первичных мероприятий по повышению эффективности российской системы финансового мониторинга можно улучшить:

- систему финансовой разведки: обязать декларировать активы, перемещаемые внутри Евразийского экономического союза.

- систему расследования ФТ: обновить стратегию по противодействию ФТ, сделав акцент на изменившемся характере риска; задействовать такие структуры, как МВД и ФСБ, в процессе депортации подозреваемых в ФТ в третьи страны.

\section{Выводы}

Подводя итог проведённому исследованию, необходимо отметить, что в результате анализа отечественной и зарубежной литературы было выявлено, что российская система финансового мониторинга подвержена значительным рискам в рамках отмывания денег. Согласно статистике большинство преступных доходов получены в результате совершаемых в стране коррупционных преступлений, которые остаются на исторически высоком уровне. Кроме того, согласно исследованиям, проведённым экспертами ФАТФ, Россия является транзитной страной и страной конечного назначения 
наркотрафика. Более того, согласно результатам национальной оценки рисков от 2018 года значительная часть преступных доходов получена в результате хищения государственных средств, совершения налоговых преступлений, злоупотребления полномочиями, а также в результате мошенничества в финансовом секторе.

Однако на основании результатов исследования можно утверждать, что эффективность российской системы финансового мониторинга в целом остаётся на значительном уровне, несмотря на приводимую статистику. Подобная степень эффективности достигается за счёт развитой финансовой разведки и достаточно совершенной системы расследования и уголовного преследования за финансирование терроризма. Кроме того, российские власти обладают достаточным пониманием существующих в стране рисков ОД/ФТ, которые в свою очередь хорошо определены и понятны всем государственным органам, а также финансовым учреждениям. Наравне с этим в стране налажена и автоматизирована система по постановке приоритетов в отношении получаемых Росфинмониторингом финансовых данных, а также реализован постоянный доступ к этим данным правоохранительными органами.

В целях повышения эффективности российской системы финансового мониторинга были предложены мероприятия, которые целесообразно разделить на 3 уровня. В первую очередь проводятся улучшения в рамках тех критериев эффективности, которые получили наименьший рейтинг: система надзора, превентивные меры, расследование и уголовное преследование за ОД, превентивные меры в рамках ФТ и целевые финансовые санкции, методы борьбы с распространением ОМП. Затем проводятся мероприятия по повышению эффективности системы относительно тех критериях, по которым получена средняя оценка: понимание рисков, политики и координации, международное сотрудничество, меры в отношении юридических лиц и договорённостей, система конфискации. И в последнюю очередь реализуются направления развития системы по критериям с наивысшей оценкой: финансовая разведка, расследование и уголовное преследование за ФТ.

\section{Список литературы}

1. Национальная оценка рисков легализации (отмывания) преступных доходов. Основные выводы. 2017-2018 [Электронный ресурс] // Росфинмониторинг. - URL: http://www.fedsfm.ru/content/files/documents/2018/ публичная\%20версия\%20нор\%20од\%203.4.1.pdf. 
2. Аблаева Т. Д., Бондарь А. П., Сурнина К. С. Финансовый мониторинг в кредитных организациях как одна из форм противодействия легализации преступных доходов и финансированию терроризма // Дни науки Крымского ФУ им. В.И. Вернадского. - 2016. - С. 131-137.

3. Белобжецкий И.А. Финансовый контроль и новый хозяйственный механизм. М.: Финансы и статистика. - 1999. - 255. - С. 9.

4. Братко А.Г. Правоохранительная система (вопросы теории). - М.: Юридическая литература. - 1991. - 208 с.

5. Буров В.Ю. Опыт Российской Федерации по противодействию оттоку капитала за рубеж и легализации доходов, полученных преступным путём // Теневая экономика. - 2019. - Том 3. - № 3. - С. 153-164.

6. Бурцев В.В. Государственный финансовый контроль: методология и организация. - М. $-2000 .-390$ с.

7. Глотов В.И., Короткий Ю.Ф., Гобрусенко К. И. Введение в курс «Финансовые расследования» в государственном финансовом мониторинге (на примере Росфинмониторинга): уч. пособие // М.: МФЮА. - 2015. - 88 с.

8. Едронова В.Н. Развитие системы финансового мониторинга в Российской Федерации // Национальные интересы. - № 5. - 2016. - С. 4-17.

9. Кондратьева Е.А. Процессы противодействия легализации (отмыванию) доходов, полученных преступным путём, и финансированию терроризма (ПОД/ФТ): категориальные подходы // Теневая экономика. - 2017. - Том 1. - № 1. - С. 31-46. doi: 10.18334/tek.1.1.37716.

10. Кричевец Е. А. Финансовый мониторинг в коммерческих банках в условиях цифровизации экономики // Наука без границ. - 2019. - № 4. - С. 5-9.

11. Морозов $\quad$ Е.С. Концептуальные подходы к повышению эффективности мониторинга по противодействию легализации незаконных доходов // Вестник ФА. - 2010. - С. 46-51.

12. Овсянников С. В. Финансовый мониторинг как инструмент кризисноустойчивого развития предприятия // Территория науки. ВЭПУ. - 2015. - № 4. - C. 196-202.

13. Прошунин М. М. Финансово-организационные вопросы организации финансового мониторинга // Проблемный анализ и государственноуправленческое проектирование. - 2009. - С. 78-87.

14. Прошунин М. М. Финансовый мониторинг как вид финансового контроля // Вестник ТГУ. - 2010. - №330. - С. 105-109. 
15. Прошунин М. М., Татчук М. А. Финансовый мониторинг / учебник. Калининград: изд-во БФУ им. И. Канта. - 2014. - 417 с.

16. Чиханчин Ю. А., Братко А.Г. Финансовый мониторинг / учебное пособие. - М. - 2018. - Том 1 - 696 с.

17. Ernst\&Young, РФПИ, ЦНИР. Исследование оттока капитала из РФ: от мифов к реальности [Электронный ресурс] - URL: http://nisse.ru/upload/ iblock/617/ottok_capitala.pdf.

18. FATF (2016), Anti-money laundering and counter-terrorist financing measures - United States, Fourth Round Mutual Evaluation Report, FATF, Paris [Электронный ресурс] - URL: www.fatf-gafi.org/publications/mutualevaluations/ documents/mer-united-states-2016.html.

19. FATF (2018), Anti-money laundering and counter-terrorist financing measures - United Kingdom, Fourth Round Mutual Evaluation Report, FATF, Paris [Электронный pecypc] - URL: http://www.fatf-gafi.org/publications/ mutualevaluations/documents/mer-united-kingdom2018.html.

20. FATF (2019), Anti-money laundering and counter-terrorist financing measures - People's Republic of China, Fourth Round Mutual Evaluation Report, FATF, Paris [Электронный ресурс] - URL: http://www.fatf-gafi.org/publications/ mutualevaluations/documents/mer-china-2019.html.

21. FATF (2019), Anti-money laundering and counter-terrorist financing measures - Russian Federation, Fourth Round Mutual Evaluation Report, FATF, Paris [Электронный pecypc] - URL: http://www.fatf-gafi.org/publications/ mutualevaluations/documents/russian-federation-2019.html.

22. FATF (2019), Anti-money laundering and counter-terrorist financing measures - Norway, 5th Year Follow-Up Assessment Report of Norway, FATF, Paris [Электронный pecypc] - URL: http://www.fatf-gafi.org/publications/ mutualevaluations/documents/fuar-norway-2019.html.

23. World Bank Open Data [Электронный pecypc] - URL: https://data.worldbank.org/. 